\title{
O impacto da institucionalização da Educação a Distância na implementação do Ensino Remoto Emergencial: o caso da Universidade Federal do Rio Grande do Sul durante a pandemia de COVID-19
}

\author{
Paulete Fridman Schwetz ${ }^{1}$ \\ Dinara Dal Pai ${ }^{2}$ \\ Jocelise Jacques de Jacques ${ }^{3}$ \\ Anelise Todeschini Hoffmann ${ }^{4}$
}

\section{RESUMO}

Este Este artigo discute a influência da institucionalização da Educação a Distância (EaD) na implementação do Ensino Remoto Emergencial (ERE) em instituições de ensino superior durante a pandemia de Covid-19 em 2020 no Brasil. O objetivo é compreender o impacto da experiência institucional em EaD no processo de implementação do ERE. O caso da Universidade Federal do Rio Grande do Sul (UFRGS), tomado como exemplo neste trabalho, sugere que o desenvolvimento prévio de tecnologias digitais voltadas à EaD pela instituição, bem como a existência de uma estrutura organizacional para a gestão acadêmica da EaD, foram fundamentais para um processo de implementação do ERE.

Palavras-chave: educação a distância, tecnologias digitais, ensino remoto emergencial.

\footnotetext{
pauletefs@gmail.com - Universidade Federal do Rio Grande do Sul

2 dinaradalpai@hotmail.com - Universidade Federal do Rio Grande do Sul

3 jocelise.jacques@ufrgs.br- Universidade Federal do Rio Grande do Sul

${ }^{4}$ anelise.hoffmann@ufrgs.br - Universidade Federal do Rio Grande do Sul
} 
The impact of the institutionalization of Distance Learning on the implementation of Emergencial Remote Teaching: the case of the Federal University of Rio Grande Do Sul during the COVID-19 pandemic

\section{ABSTRACT}

This paper discusses the influence of the institutionalization of Distance Learning (DL) on the implementation of Emergency Remote Teaching (ERT) in higher education institutions during the Covid-19 pandemic in Brazil in 2020. The aim is to understand the impact of the institutional experience in DL on the process of implementation of ERT. The Federal University of Rio Grande do Sul (UFRGS)'s case, taken as an example in this work, suggests that the previous development of digital technologies aimed at DL by the institution, as well as the existence of an organizational structure for the academic management of $D L$, were fundamental for the implementation process of ERT.

Keywords: Distance Education. Digita technologies. Emergency Remote Teaching. 
O uso das tecnologias digitais como forma de promover a desejada transformação das experiências de aprendizagem nas instituições de ensino já é um caminho bastante conhecido e discutido pela literatura que trata da relação entre tecnologia e educação (FERREIRA, BRANCHI; SUGAHARA, 2020; NETTO, 2005; TAPSCOTT, 1999). Os recursos tecnológicos são facilitadores do processo de ensino e aprendizagem, na medida em que, favorecem o trabalho em equipe dos professores e motivam a participação dos alunos. No entanto, a incorporação desses recursos nos ambientes educacionais esbarra na falta de preparação técnica dos professores, tornando sua utilização bastante restrita na experiência de aprendizagem presencial (FALAVIGNA, 2009). Apesar de representar uma novidade, o processo de inserção de tecnologias nos ambientes educacionais tende a ser conservador, pautando-se pela adaptação dos novos recursos ao contexto convencional do ensino presencial (FERREIRA, BRANCHI; SUGAHARA, 2020; TAPSCOTT, 1999). O computador, por exemplo, foi por muito tempo utilizado na sala de aula apenas para substituir antigas ferramentas como o caderno, o quadro negro e a enciclopédia, não significando mudanças substanciais na condução do processo de aprendizagem.

Em 2020, porém, esse cenário mudou radicalmente, por conta da pandemia de Covid19 e da necessidade de medidas sanitárias de distanciamento social, as quais suspenderam as atividades de ensino presenciais de muitas escolas e universidades mundo afora. Em pouco tempo, docentes necessitaram adaptar os seus planos de aula para o modelo do Ensino Remoto Emergencial (ERE), passando a utilizar Ambientes Virtuais de Aprendizagem (AVAs) para a comunicação com as turmas e tendo de se familiarizar com toda uma série de aplicativos e plataformas que possibilitavam o desenvolvimento das competências e habilidades previstas nas atividades de ensino. No ERE, os processos de ensino-aprendizagem passaram a ser mediados por Tecnologias de Informação e Comunicação (TICs) garantindo que alunos e professores pudessem interagir a partir de suas moradias, participando das aulas com flexibilidade de espaço e, em muitos casos, de tempo (MOREIRA; SCHLEMMER, 2020).

Sabe-se que a difusão da qualquer tecnologia está condicionada por questões históricas, geográficas e culturais e seu uso e significado é determinado pelas práticas humanas (NYE, 2006). O ERE foi um exemplo disso, embora já disponíveis e conhecidas pelos profissionais da Educação a Distância (EaD), foi preciso uma ruptura histórica das práticas de ensino-aprendizagem nas salas de aula presenciais para que as tecnologias digitais pudessem encontrar lugar nos mais variados ambientes educacionais, sem restrições e enquadramentos relativizando a sua importância. Nesse contexto de situação emergencial que exigia uma rápida adaptação das práticas de ensino-aprendizagem, a EaD surgiu como uma das principais referências, reacendendo a discussão sobre a qualidade do ensino nessa modalidade e as possibilidades de efetiva apropriação de TICs por parte dos professores.

Esse debate torna-se relevante pelas frequente e equivocadas discussões que, muitas vezes, consideram o ERE e a EaD como sinônimos de processos de ensino- aprendizagem mediados por TICs. Mesmo que as comparações sejam inevitáveis, é certo que cada um desses modelos atende a demandas bastante específicas. A EaD envolve um processo complexo de ensino-aprendizagem, pois mais que o envio de conteúdo educacional, exige dos alunos autonomia, responsabilidade, flexibilidade e escolhas, requerendo um planejamento cuidadoso de concepção e determinação de objetivos para ser eficaz, o que dificilmente pode contemplado pelo ERE (BOZKURT; SAHRMA, 2020). Por isso, "a configuração de modelos de 
hardware e software para a educação a distância requer do profissional, que as desenvolve, o conhecimento dos pressupostos pedagógicos subjacentes a sua constituição". (NETO, 2005, p. 100). Assim, mostra-se indispensável o conhecimento, por parte dos educadores, de modelos pedagógicos específicos para qualificar as interações a distância (BEHAR, 2008; MOREIRA; SCHLEMMER, 2020), sem os quais a aplicação de novas tecnologias pode até mesmo prejudicar ao invés de favorecer o processo de ensino e aprendizagem.

No caso do EaD, se a tecnologia impulsiona mudanças, não é capaz de, por si só, determinar comportamentos. As TICs são um meio para diminuir a "distância pedagógica" entre os atores envolvidos, assegurando formas de comunicação e interação que contribuam na construção de conhecimento, mas o que determina as escolhas das ferramentas e a qualidade da experiência vivenciada são os pressupostos pedagógicos e sua adequação ao perfil dos atores envolvidos (MOREIRA; SCHLEMMER, 2020; BEHAR, 2008; 2009).

Considerando a problemática exposta, este artigo discute a influência da institucionalização da EaD na implementação do ERE em instituições de ensino superior. A partir do estudo do caso da Universidade Federal do Rio Grande do Sul (UFRGS), uma das mais importantes instituições de ensino superior do país, busca-se responder ao seguinte problema de pesquisa: como a experiência institucional com a EaD impacta a implementação do ERE nas instituições de ensino superior? Visando alcançar tal objetivo, a exposição do argumento está organizada em duas seções principais. Na seção 2, por meio de uma revisão de literatura, são delineadas as semelhanças e diferenças entre a EaD e do ERE, considerando contextos e tecnologias implicadas. Na seção 3, apresenta-se um estudo de caso sobre a experiência da UFRGS durante a pandemia de Covid-19 em 2020 no Brasil, onde é apresentada uma análise da influência da EaD na implementação do ERE.

A Essa seção apresenta, por meio de pesquisa bibliográfica, as particularidades que caracterizam a EaD e o ERE no contexto brasileiro, considerando definição, evolução tecnológicas, recursos humanos e qualidade. Assim, o objetivo dessa seção é compreender as semelhanças e diferenças entre os modelos da EaD e do ERE.

\subsection{Educação a Distância}

Historicamente considerada como um caminho promissor para a democratização do ensino, a EaD permite que pessoas em grande número, mesmo distantes fisicamente, possam acessar variados tipos de saberes de cunho acadêmico e profissional (SANTINELLO, 2015). Além do termo Educação a Distância, utilizado neste artigo, Moore et al. (2011) destacam o uso de outras terminologias a nível global como e-learning, ensino online e ensino a distância. Para o autor, não existe uma visão comum sobre o que caracteriza cada uma dessas expressões, fato que pode gerar obstáculos para a pesquisa na área. No entanto, destaca-se que a compreensão das características das diferentes propostas de ensino e aprendizagem podem ser pontos de partida ainda mais interessantes para o estudo dos processos de aprendizagem que ocorrem a distância.

Embora seja reconhecida como uma modalidade de ensino fortemente ligada às tecnologias digitais, as origens da EaD remontam ao século XIX, tempo em que a informação ainda circulava por meio de correspondências e substratos tangíveis (MACHADO; MORAES, 2015; SANTINELLO, 2015). Ao analisar as transformações históricas da EaD e sua relação com 
os avanços tecnológicos, Machado e Moraes (2015) destacam cinco gerações nas quais destacam-se, respectivamente, o uso do correio e da ferrovia, do rádio, da transmissão via satélite e a criação da rede mundial de computadores. No entanto, a partir da terceira geração, situada na década de 1960, é reconhecida a importância de uma visão pedagógica específica para a EaD, colocando a tecnologias em segundo plano e passando a compreendêla como suporte para o processo de ensinar e aprender.

No Brasil, os cursos de profissionalização por correspondência e via rádio também estiveram entre as primeiras experiências de educação que não exigiam a presença física do professor e do aluno ao mesmo tempo (SANTINELLO, 2015; MACHADO; MORAES, 2015). Já nas décadas de 1970 e 1980, fundações privadas e organizações não governamentais disseminaram a oferta de cursos supletivos a distância, no modelo de teleducação, com aulas via satélite, complementadas por materiais impressos (ALVES, 2011).

No caso das instituições de ensino superior, foi apenas na última década do século XX, com as novas TICs, que surgiram as primeiras iniciativas de oferta da EaD. A Lei de Diretrizes e Bases da Educação, de 1996, respaldou a implementação da EaD, nos diversos níveis de ensino, como uma modalidade educacional na qual as TICs são utilizadas como mediadoras dos processos de ensino-aprendizagem, permitindo que alunos e professores desenvolvam atividades em lugares ou tempos diversos (BRASIL, 2007). Em 2005, o MEC definiu critérios que servem como base para as instituições que trabalham ou pretendem trabalhar com essa modalidade de ensino. Buscou-se, por meio disso, qualificar os processos, reduzir a evasão e coibir a precarização da educação superior, verificada em alguns modelos de oferta que acabavam por isolar o estudante (BRASIL, 2007).

No entanto, sabe-se que o constante avanço das TICs tem o potencial de melhorar, progressivamente, as relações humanas em ambientes virtuais, ampliando as alternativas para a aprendizagem em grupos cooperativos (NETO, 2005). Nesse sentido, observa-se que

embora avanços importantes tenham acontecido nos últimos anos, ainda há um caminho a percorrer para que a Educação a Distância possa ocupar um espaço de destaque no meio educacional, em todos os níveis, vencendo, inclusive, o preconceito de que os cursos oferecidos na Educação a Distância não possuem controle de aprendizado e não têm regulamentação adequada. (ALVES, 2011, p. 90).

A Secretaria de Educação a Distância do MEC apresenta um documento que tem como objetivo propiciar debates, reflexões e definir Referenciais de Qualidade para a modalidade de educação superior a distância no País (BRASIL, 2007). Assim, para que seja alcançada a qualidade desejada, destaca-se a necessidade de compreender a educação como fundamento primeiro, a partir de uma discussão política e pedagógica da ação educativa que repercute no modo de organização e na relação dos aspectos pedagógicos, recursos humanos e infraestrutura da EaD.

Conforme o documento, para atuar nessas dimensões, considera-se fundamental organizar o Projeto Pedagógico dos cursos dessa modalidade a partir de oito pontos: (i) concepção de educação e currículo no processo de ensino e aprendizagem; (ii) sistema de comunicação; (iii) material didático; (iv) avaliação; (v) equipe multidisciplinar; (vi) infraestrutura de apoio; (vii) gestão acadêmico-administrativa; e (viii) sustentabilidade financeira (BRASIL, 2007).

O primeiro ponto, concepção de educação e currículo no processo de ensino e aprendizagem, considera a importância da definição e da apresentação clara da opção epistemológica de educação, de currículo, de ensino, de aprendizagem e de perfil de egresso que se pretende alcançar, buscando sempre a integração entre conteúdo e metodologia. Essa 
noção torna-se fundamental para a construção do modelo pedagógico, bem como para o planejamento e o desenvolvimento dos demais pontos listados (BRASIL, 2007).

Segundo Behar (2009), o modelo pedagógico EaD define o tipo de relação que vai existir entre os sujeitos envolvidos no processo de ensino e aprendizagem. Nessa perspectiva, o triângulo aluno, professor e objeto de estudo é organizado de acordo com um conjunto de premissas teóricas que representam, explicam e orientam a forma como o currículo será abordado. A autora também aponta a necessidade de preparação do aluno para atuar nessa modalidade de ensino, uma vez que o ambiente educacional virtual ainda representa uma novidade para a maioria dos estudantes. Recomenda-se, assim, a criação de um módulo introdutório no AVA para acolhimento, preparação do aluno e comunicação de habilidades básicas fundamentais ao uso das tecnologias necessárias (BEHAR, 2008; BRASIL, 2007).

Em relação ao sistema de comunicação, segundo ponto listado, o documento ressalta a importância das interações e do diálogo entre os atores envolvidos no processo de ensino e aprendizagem (professores, tutores, alunos e funcionários técnico-administrativos) e o acesso facilitado aos conteúdos, cronograma e atividades.

Por outro lado, a comunicação assíncrona é realizada em tempos diferentes, permitindo maior flexibilidade para a interação. Exemplos de tecnologias com foco nesse tipo de comunicação é o correio eletrônico e as videoaulas gravadas. Além disso, o autor observa que essas ferramentas podem prever formas de comunicação do tipo um para um (apenas uma pessoa envia a mensagem e outra recebe), um para muitos (apenas uma pessoa envia a mensagem e muitas recebem) e muitos para muitos (várias pessoas enviam a mensagem e várias recebem) (RODRIGUES,2002).

A forma mais usual de comunicação na EaD é a assíncrona em função das características do próprio tipo de ensino, pois ela propõe uma liberdade de escolha, tanto de tempo como de espaço, para que ocorra a aprendizagem.

No que diz respeito ao material didático, sua concepção deve considerar o apoio de uma equipe multidisciplinar formada por professores e especialistas em área como desenho instrucional, diagramação, ilustração e webdesign e estar alinhada aos princípios epistemológicos, metodológicos e políticos explicitados no projeto pedagógico. Além disso, o material didático deve ser testado e, se necessário, aperfeiçoado antes de ser disponibilizado aos alunos (BRASIL, 2007).

A empatia é fundamental para o desenvolvimento de experiências de $\mathrm{EaD}$, conforme Matthews et al. (2017). Nesse sentido, são criticadas ações que consideram o aluno como alguém sem identidade, necessidades, gostos e experiências de vida. Matthews et al. (2017), apresentam um estudo que mostra como um grupo de designers enxerga a empatia na prática projetual da EaD e como é possível exercitá-la e utilizá-la nas práticas reais. A empatia surge pela preocupação e cuidado dos designers com a experiência de aprendizagem proposta para o aluno, pelas memórias de quando eram estudantes e pelo exercício de imaginação que os coloca no papel do discente. Em relação às estratégias utilizadas, o estudo destacou o uso de técnicas informais e de escolha pessoal como a criação de personas, a escuta de chamadas do atendimento, a realização de pesquisas e as conversas informais com colegas de trabalho.

O quarto ponto considera a avaliação e assinala a sua importância a partir do acompanhamento da aprendizagem do aluno, de forma a identificar eventuais dificuldades e oferecer suporte durante o percurso do curso. A legislação brasileira impõe a necessidade de avaliações presenciais para a certificação dos alunos que realizam cursos EaD. Segundo Machado e Moraes (2015), os encontros presenciais previstos hoje nos cursos dessa modalidade tiveram o seu início por volta das décadas de 1970 e 1980, na chamada quarta 
geração da $\mathrm{EaD}$, quando a necessidade de equipamentos específicos para a transmissão via satélite exigiu a organização de espaços físicos. Assim, mesmo com a disseminação das novas tecnologias digitais e da internet, os momentos avaliativos seguem sendo presenciais e obrigatórios pela legislação, fato que pode refletir a dificuldade de criação de alternativas para o tradicional instrumento de avaliação focado na realização de provas e na memorização de conteúdos.

Outro ponto prevê a implementação de sistemas de avaliação institucional, incluindo ouvidoria. Esta avaliação deve configurar-se em um processo permanente que é divulgado ao aluno e considerar aspectos como organização didático-pedagógica, infraestrutura, corpo docente, corpo de tutores, corpo técnico- administrativo e discentes (BRASIL, 2007).

Em relação às equipes multidisciplinares, quinto ponto destacado no documento, considera-se a importância dos recursos humanos e de sua diversidade, sendo essenciais para uma oferta de curso EaD: os professores, os tutores e os funcionários técnico- administrativos (BRASIL, 2007).

Os professores devem ser capacitados e atualizados com frequência, sendo capazes de estabelecer os fundamentos teóricos do projeto, selecionar e preparar os conteúdos, avaliar os estudantes etc. Esse profissional deve também apoiar o estudante no uso da ferramenta empregada no ensino a distância, além de incentivá-lo a interagir com certa frequência (BRASIL, 2007; NETO, 2005). Na perspectiva de Neto (2005),

com o uso dos programas a distância, as atividades de lecionar e avaliar os alunos são diferentes da forma na qual são realizadas em uma classe de aula tradicional. Os computadores fazem com que os educadores dispendam menos tempo em lecionar diretamente, mas de forma alguma diminui a importância do papel do educador. O papel do educador passa a ser o de orientar e ajudar os alunos a manter as informações no contexto do trabalho, o que requer um conhecimento detalhado do processo de aprendizagem (NETO, 2005. p.101).

Nesse sentido, Machado e Moraes (2015) observam que, na EaD, o professor também é um aprendiz, uma vez que docentes e discentes são convidados a desenvolver novas competências, como o domínio de múltiplas linguagens e a resolução de problemas complexos.

$\mathrm{Na}$ experiência de aprendizagem EaD, os tutores também são considerados profissionais essenciais, pois devem dominar o conteúdo e participar ativamente da prática pedagógica, contribuindo para o acompanhamento e avaliação do projeto pedagógico. A tutoria a distância é focada no esclarecimento de dúvidas, individuais e coletivas, por meio do uso de TICs que devem ser especificadas no projeto pedagógico. Já o trabalho de tutoria presencial prevê o uso dos polos e exige que horários sejam previamente agendados (BRASIL, 2007).

O corpo técnico-administrativo deve oferecer o apoio necessário para a realização do curso ofertado, atuando na sede da instituição e nos polos descentralizados. As atividades desempenhadas por esses profissionais envolvem duas dimensões principais: a administrativa (secretaria acadêmica para realização de matrículas, avaliação e certificação) e a tecnológica (auxílio na produção dos materiais didáticos, manutenção e suporte técnico para uso de laboratórios e biblioteca). Além disso, destaca-se o papel do coordenador do polo de apoio presencial como o responsável pelo funcionamento dos processos administrativos e pedagógicos que se desenvolvem na unidade (BRASIL, 2007). 
A infraestrutura de apoio, sexto ponto listado no documento, deve ser compatível com o número de estudantes e com o território que se deseja alcançar. A infraestrutura material deve estar presente na sede da instituição e nos polos de apoio presencial e deve disponibilizar equipamentos para produção audiovisual, computadores, televisão, impressoras, acesso a rede de internet dentre outros recursos. Nas unidades de suporte ao planejamento, produção e gestão dos cursos a distância, a infraestrutura básica é composta por secretaria acadêmica, salas de coordenação, salas para tutoria a distância, biblioteca, sala de professores, laboratório de informática e, se possível, sala específica para videoconferência. As salas de informática desempenham papel primordial neste tipo de curso, pois precisam garantir o acesso ao ambiente virtual de aprendizagem projetado para o curso, a interação dos estudantes, docentes, coordenador de curso e funcionários (BRASIL, 2007).

Sobre a gestão acadêmico-administrativa, ressalta-se a importância do acesso facilitado do estudante dessa modalidade de ensino a todos os serviços disponibilizados pela instituição, bem como a gestão de todos os processos e zelo pelo bom funcionamento das atividades propostas. Além disso, o sistema deve permitir a autonomia docente e a flexibilidade para a elaboração e gerenciamento de conteúdo e atividades (BRASIL, 2007).

Por fim, o oitavo e último ponto considera a necessidade de sustentabilidade financeira desse sistema, uma vez que são grandes os investimentos em infraestrutura e recursos humanos para viabilizar a implementação de um curso a distância.

\subsection{Ensino Remoto Emergencial}

O ERE, termo que se popularizou em 2020, caracterizou-se como uma resposta rápida à demanda de suspensão das atividades educacionais presenciais e na sua adaptação, por meio do uso de tecnologias, para viabilizar a continuidade dos estudos em circunstâncias que não exigem a presença física do professor e dos alunos no mesmo espaço. Segundo Hodges et al. (2020), Moreira e Schlemmer (2020), diferente da experiência EaD, o ERE é uma alternativa temporária para não cessar o ensino em tempos de crise, sem a possibilidade de amplo planejamento para a sua implementação.

O principal objetivo, nessas circunstâncias, não é recriar um ecossistema educacional robusto, mas oferecer acesso à educação de uma forma ágil, segura e temporária (HODGES et al. 2020). Essa percepção permite diferenciar o ERE da EaD que, conforme já descrito no item anterior, exige uma ampla infraestrutura, tempo de planejamento, trabalho multidisciplinar e a criação de modelo pedagógico distinto daquele utilizado para os cursos presenciais. Para Bozkurt e Sharma (2020), uma distinção significativa entre os dois modelos está na forma como os alunos são envolvidos no processo. Enquanto a EaD é uma alternativa flexível para a modalidade presencial e configura-se como uma opção dos alunos, o ERE é uma obrigação diferente da opção original pelas aulas presenciais.

A pandemia pelo Covid-19 é a primeira crise de dimensões globais, mas outras crises, de menor abrangência, já exigiram a utilização de estratégias para atender a necessidades de ensino a distância (BOZKURT; SHARMA, 2020). Nesse sentido, Hodges et al. (2020) apresentam um estudo realizado pela Agency Network for Education in Emergencies que examinou quatro casos na perspectiva da educação em situações de fragilidade e emergência. Um desses casos foi o Afeganistão, onde a educação foi interrompida por conflito e violência, devido ao fato de as meninas estarem frequentando a escola. Para tirar as crianças das ruas e mantê-las seguras, o ensino foi adaptado para ocorrer via rádio e DVDs.

O que fica evidente em uma situação de crise que apela para o ensino remoto é o uso de uma infraestrutura e de tecnologias já disponíveis e difundidas no contexto em que é 
aplicado. Além da criatividade para solucionar os problemas que são, muitas vezes, inevitáveis em um processo rápido de implementação.

Conforme já mencionado, em 2020, o ERE foi utilizado como alternativa à necessidade de distanciamento social ocasionado pela pandemia. Nesse cenário as universidades brasileiras, seguindo o exemplo das instituições europeias, asiáticas e norte-americanas, migraram as suas aulas para o ERE, utilizando os AVAs para gerenciar a comunicação e atividades de maneira síncrona e assíncrona. Ressalta-se, no entanto, que essa migração não foi uniforme em todas as instituições de ensino superior que acabaram contando com tempos e infraestruturas tecnológicas diferentes.

No caso brasileiro, registrou-se uma diferença entre o tempo de adaptação das instituições privadas e públicas. Enquanto as primeiras tiveram que iniciar o ERE em poucos dias (temendo perder alunos e, consequentemente, a sustentabilidade financeira), retomando as atividades em ambiente virtual rapidamente, as segundas optaram por um maior tempo de adaptação, somando meses onde a grande maioria das atividades de aulas foram paralisadas, como é o caso da UFRGS.

Segundo Rondini (2020), no ERE, as tecnologias digitais, antes utilizadas como recursos de apoio ao processo de ensino e aprendizagem, converteram-se em um recurso fundamental no ensino remoto, exigindo de professores e alunos um aprendizado intenso de novas tecnologias, bem como o uso da infraestrutura privada de suas das casas. Nesse estudo realizado com professores de escolas públicas e privadas do Estado de São Paulo, foram enfatizadas, em relação às dificuldades desse modelo, a adaptação rápida a uma nova metodologia de ensino, a desigualdade social e de infraestrutura dos estudantes (situação que é distinta em instituições públicas e privadas), bem como o aumento considerável da jornada de trabalho em ambientes virtuais.

Hodges et al. (2020) chama a atenção para a ampliação das demandas dos setores técnicos de apoio ao corpo docente que, muitas vezes, não são capazes de atender de forma adequada a todas as solicitações individuais com a urgência que a situação do ERE requer. Para os autores, o contexto emergencial exige que as instituições desenvolvam novas estratégias para dar continuidade ao ensino em ambiente virtual, ao mesmo tempo que apoiam o corpo docente a desenvolver habilidades para trabalhar com diferentes mídias. Nessa perspectiva, fica clara a necessidade de ações de formação coletiva, tendo em vista a identificação de necessidades comuns a todos os professores e orientações em relação às melhores práticas nesse cenário que é distinto daquele no qual os professores já eram acostumados a trabalhar.

Nesse tipo de situação, verifica-se que o ERE trouxe a necessidade de mudanças nas competências de docentes e discentes para a vivência de uma experiência de aprendizagem significativa. Em um cenário onde as interações ocorrem por meio de TICs, as limitações das práticas pedagógicas tradicionais focadas na transmissão dos conteúdos ficam evidentes. Cabe ao profissional da docência apropriar-se das ferramentas computacionais como forma de promover a construção do conhecimento. Da mesma forma, também o discente precisa se tornar sujeito do processo de ensino e aprendizagem. Para isso, é necessária autonomia, desejo de aprender, organização e planejamento do estudo.

Também cabe problematizar a avaliação que muitas instituições realizaram para entender a percepção dos atores envolvidos em relação ao "sucesso" do ERE. Segundo Hodges et al. (2020), não é possível comparar essa experiência com aquela proposta pelo curso presencial ou EaD, uma vez que são situações distintas, com necessidades e finalidades específicas. Nesse sentido, sugere-se considerar as particularidades do contexto, avaliando necessidades, problemas e oportunidades, bem como o plano de ação, os custos, o 
envolvimento de pessoas, o atendimento das necessidades e o alcance das metas e resultados. Evidencia-se, assim, a importância do monitoramento de todo o processo, registrando e documentando a experiência de implementação do ERE. Whittle et al. (2020) também chamam a atenção para a importância de que o ERE motive o desenvolvimento de novas pesquisas e a criação de modelos a partir dos aprendizados que estão sendo adquiridos.

Em tempos de crise, quando as pessoas estão sob estresse e pressão psicológica, parece oportuno focar os esforços educacionais na formação de um ser humano com responsabilidade social, preparado para compartilhar, colaborar e apoiar os colegas em momentos de dificuldade. Em um cenário pós-pandemia, quando realmente será possível optar pelo melhor ambiente de ensino e aprendizagem, seja ele físico ou virtual, as pessoas não irão se lembrar do conteúdo educacional entregue no ERE, mas de como se sentiram e o que fizeram diante das mudanças e incertezas (BOZKURT; SHARMA, 2020). Talvez a experiência do ERE represente a hora de abandonar a ideia de que a educação tem como principal objetivo transmitir conhecimentos apoiados por ferramentas tecnológicas que são adaptadas para manter os antigos vícios das aulas expositivas.

\section{O CASO DA UFRGS: O IMPACTO DA EAD NO ERE}

Nesta seção, a partir do estudo de caso sobre a experiência institucional da UFRGS durante a pandemia de Covid-19 em 2020 no Brasil, analisa-se o impacto da EaD na implementação do ERE.

\subsection{Desenho Metodológico}

Diante do objetivo de entender a influência da institucionalização da $\operatorname{EaD}$ na implementação do ERE, o presente artigo utiliza uma abordagem qualitativa, de caráter exploratório e descritivo. Desenvolveu-se uma investigação empírica de tipo estudo de caso que, segundo Gil (1999), caracteriza-se por apresentar um estudo profundo e exaustivo de um ou de poucos objetos, permitindo o conhecimento amplo e detalhado de sua realidade e contexto. A unidade de estudo selecionada para a realização deste estudo foi a UFRGS e a estratégia de coleta de dados contou com uma pesquisa documental objetivando analisar os pressupostos que orientaram a implementação do ERE e sua relação com a EaD institucionalizada.

\subsection{Contexto Institucional}

A UFRGS é reconhecida como a primeira instituição a oferecer cursos de educação superior no Estado do Rio Grande do Sul. Inicialmente denominada Universidade de Porto Alegre, a UFRGS inicia a sua trajetória enquanto universidade em 1934. Em 1947, com a incorporação das Faculdades de Direito e de Odontologia de Pelotas e da Faculdade de Farmácia de Santa Maria (que mais tarde deram origem a Universidade Federal de Pelotas e à Universidade Federal de Santa Maria, respectivamente) passa a ser chamada de Universidade do Rio Grande do Sul. No ano de 1950, a instituição é federalizada, e passa a ter a denominação atual (UFRGS, 2019).

A UFRGS tem como base a tríade ensino, pesquisa e extensão e oferece cursos de graduação, pós-graduação e cursos técnicos. Em 2019, a instituição foi eleita, pelo $8^{\circ}$ ano consecutivo, a melhor universidade federal do Brasil pela avaliação realizada pelo Instituto Nacional de Estudos e Pesquisas Educacionais Anísio Teixeira (Inep), do MEC (UFRGS, 2019).

Em relação a sua infraestrutura, a UFRGS possui cinco campi, sendo quatro localizados em Porto Alegre e um no Litoral Norte, uma Estação Experimental Agronômica em 
Eldorado do Sul e dezessete polos descentralizados para a promoção de cursos de EaD de graduação e pós-graduacão pelo Estado do Rio Grande do Sul (UFRGS, 2019). Possui uma comunidade acadêmicas de mais de 2.800 professores que atuam desde o Ensino Fundamental até a Pós-Graduação (de forma permanente ou temporária), cerca de 2.500 funcionários técnico-administrativos e mais de 30 mil alunos (UFRGS, 2020)

$\mathrm{Na}$ estrutura de governança, destacam-se o Conselho Universitário (CONSUN) e o Conselho de Ensino, Pesquisa e Extensão (CEPE), o Conselho de Curadores (CONCUR), Comitê de Governança, Riscos e Controles (CGRC), Comitê de Governança Digital (CGD), Conselho Consultivo de Gestão, Grupos de Processo (GP), a Auditoria Interna (AUDIN) e a Ouvidoria. Além disso, a UFRGS possui um modelo de gestão de Tecnologia da Informação (TI) que tem por finalidade "prover, manter e gerenciar os recursos de tecnologia da informação de forma a apoiar e viabilizar as atividades de ensino, pesquisa, extensão e gestão administrativa da Universidade" (UFRGS, 2019, p. 161).

A escolha desta instituição e, mais especificamente, da graduação para o desenvolvimento deste estudo levou em conta a histórica relação entre as tecnologias da informática e a educação promovida pela UFRGS desde os anos 1970 (esse tópico será aprofundado na seção sobre o EaD na UFRGS), bem como sua reconhecida excelência acadêmica e transparência no acesso às informações e dados institucionais. Ressalta-se ainda que, no ano 2002, foi criada a Secretaria de Educação a Distância (SEAD/UFRGS) e a biblioteca virtual da Universidade, institucionalizando essa modalidade de formação (UFRGS, 2019; SEAD/UFRGS, 2020).

No ensino de graduação, a UFRGS ofereceu, em 2019, 97 cursos na modalidade presencial e 5 na modalidade de EaD (UFRGS, 2020). Nesse nível, são ofertadas, ao todo, cerca de 5.671 vagas sendo que o ingresso do estudante é condicionado, principalmente, pelo seu desempenho no vestibular e no Sistema de Seleção Unificada (SISU). Também estão disponíveis outros tipos específicos de seleção, como o extravestibular, estudantes indígenas, refugiados, processo seletivo unificado e os dos cursos na modalidade a distância (UFRGS, 2019, p. 68).

A partir da análise do relatório on-line disponível no portal da universidade, que apresenta a UFRGS em números (UFRGS, 2020), observa-se que, comparando-se as mudanças entre os anos de 2010 e 2019, em relação à EaD, a UFRGS teve como número máximo de oferta 8 cursos entre os anos de 2010 e 2013. De 2014 a 2016 variou entre 1 e 2 cursos, em 2017 não teve oferta e nos anos seguintes estabilizou com a oferta de 5 cursos nessa modalidade. Em relação aos laboratórios de informática, o ano de 2014 destaca-se com 154. Em 2019, esse número passa a ser de 134. A crescente ampliação do Repositório Digital LUME ao longo dos anos evidencia a tendência de digitalização de grande parte do acervo da UFRGS.

A seguir, são discutidos os processos históricos que culminaram na institucionalização da EaD na UFRGS, representada pela criação da SEAD/UFRGS, bem como a influência desse processo na implementação do ERE.

\subsection{A Institucionalização da EaD na UFRGS}

Conforme já citado, o ano de 2002 marca a institucionalização da EaD na UFRGS por meio da criação de uma secretaria específica, a SEAD/UFRGS, que busca desenvolver e implantar políticas e ações nessa modalidade de ensino, bem como realizar o aperfeiçoamento pedagógico por meio de TICs, promovendo inovações no processo de ensino e aprendizagem (SEAD/UFRGS, 2020). 
A SEAD/UFRGS é responsável pela coordenação institucional da Universidade Aberta do Brasil (UAB) desde 2006, programa do MEC que busca ampliar e interiorizar a oferta de cursos e programas de educação superior, por meio da EaD (SEAD/UFRGS, 2020; MEC, 2020). Com o intuito de apoiar a realização de cursos nessa modalidade, fomentados pela UAB, a SEAD/UFRGS conta com uma equipe multidisciplinar que tem como principais objetivos: (i) proporcionar apoio acadêmico e pedagógico; (ii) oferecer apoio tecnológico; (iii) apoiar o gerenciamento dos recursos; (iv) apoiar a produção e reprodução de material didático; (v) apoiar os processos de capacitação continuada das equipes envolvidas na implementação dos cursos; e (vi) acompanhar os polos e os cursos desenvolvidos na modalidade a distância (SEAD/UFRGS, 2020).

No entanto, ressalta-se que a história que levou à consolidação do EaD na UFRGS não iniciou com o surgimento da SEAD/UFRGS. Décadas antes, ainda nos anos 1970, a Universidade iniciou os seus primeiros projetos na área da informática e educação por meio do Laboratório de Estudos Cognitivos (LEC). Desde então, avança nas pesquisas que tentam entender os processos cognitivos em situações de aprendizagem que envolvem 0 computador. Já na década de 1980, a UFRGS destaca-se em nível nacional ao desenvolver, no âmbito do Projeto Nacional de Informática na Educação (EDUCOM), o software SISCAI que foi utilizado pelo MEC em 1989, quando da implantação do Programa Nacional de Informática na Educação (SEAD/UFRGS, 2020).

Os anos de 1990 representam uma revolução na EaD com a expansão da internet e o surgimento de novas tecnologias digitais que motivaram a ampliação das pesquisas realizadas pela UFRGS sobre esse tema. Nesse período, ocorreu a implantação do primeiro curso brasileiro de Especialização e de Pós-Graduação em Informática na Educação, viabilizaram-se os serviços de correio eletrônico e o primeiro projeto de EaD por meio de Packet-Radio, na frequência de radioamador, alcançando alunos e professores de classes de alfabetização. Além disso, começou-se a mobilizar recursos humanos, criando-se espaços para o diálogo entre docentes sobre a EaD (SEAD/UFRGS, 2020).

Nos anos 2000, ocorreu uma rápida expansão das ofertas dessa modalidade na UFRGS. Nesse contexto, com o suporte técnico do Comissão de Pesquisa e Desenvolvimento (CPD), surgiu a demanda pela criação de uma plataforma institucional integrada ao sistema de gestão acadêmica da Universidade. Então, foram desenvolvidos dois AVAs por grupos de pesquisas da UFRGS, o NAVI e o ROODA (SEAD/UFRGS, 2020). De acordo com Behar et al. (2003), o ROODA - Rede cOOperativa De Aprendizagem é um Software Livre que nasceu de um trabalho de pesquisa interdisciplinar que integrou tecnologia digital e educação no intuito de criar um AVA alternativo aos modelos focados na entrega de conteúdo, realização de exercícios e processos de memorização que reforçavam a lógica tradicional de ensino. Tendo como base a teoria construtivista de Piaget, o ROODA privilegiou a interação, a cooperação e a comunicação síncrona e assíncrona.

Em 2007, o MOODLE também foi institucionalizado tornando-se o AVA mais utilizado na EaD. Nesse mesmo ano, foram criados pela Universidade pólos de apoio presencial abrangendo diversas regiões do Rio Grande do Sul e outros estados brasileiros (SEAD/UFRGS, 2020).

A partir disso, passam a ser ofertadas formações buscando preparar os professores para o uso desses AVAs, bem como eventos que buscavam divulgar as experiências na EaD e estimular publicações sobre esse tema. Em 2009, surgiu o Núcleo de Apoio Pedagógico à Educação a Distância (NAPEAD), oferecendo suporte às ações de EaD na UFRGS, com ênfase na produção de objetos de aprendizagem digitais (SEAD/UFRGS, 2020). Carneiro e Silveira (2014) realizaram um estudo que analisou 65 objetos de aprendizagem produzidor pelo 
NAPEAD em conjunto com professores da UFRGS, destinados a diversas áreas do conhecimento e utilizando diferentes tecnologias.

No estudo buscou-se analisar as contribuições desses objetos para o processo de ensino e aprendizagem por meio da perspectiva de professores e alunos. Nos casos analisados, observou-se que a maioria dos professores busca materiais didáticos para apoiar as aulas presenciais tornando os objetos produzidos um complemento para o estudo do aluno após ou durante as aulas. Constata-se também a importância da apropriação, pela equipe, da concepção e conceito do que é um objeto de aprendizagem e o que ele deve conter, bem como a preparação dos professores para o seu uso (CARNEIRO e SILVEIRA, 2014).

Em 2011, foi implementada a Sala de Aula Virtual (SAV), ambiente de ensino online integrado ao sistema acadêmico da Universidade que oferece ferramentas digitais para controle de presenças, divulgação de notas, contato com alunos etc. (SEAD/UFRGS, 2020).

Atualmente, a SEAD/UFRGS atua no suporte às plataformas institucionais, trabalhando de forma integrada às pró-reitorias, capacitando a comunidade acadêmica, promovendo editais de fomento às ações vinculadas à EaD e realizando eventos para motivar a discussão e atualização constante na área (SEAD/UFRGS, 2020).

Com base nessa breve análise documental, nota-se que a evolução da EaD na UFRGS acompanhou as transformações das tecnologias pelo mundo, assim como ocorreu na maioria das instituições que hoje atuam nessa modalidade. No entanto, ressalta-se o potencial da construção de conhecimento institucional por meio da pesquisa e do desenvolvimento de novas tecnologias, evidentes pelo caso dos AVAs NAVI e ROODA e pelo software Mconf. $O$ Mconf foi desenvolvido pelo Laboratório de Projetos em Áudio e Vídeos da UFRGS em sistema de código aberto e busca oferecer à comunidade acadêmica um sistema completo de webconferência, com foco na facilidade de uso e integração com sistemas móveis e redes sociais (BOTTIN, 2011).

No contexto de ERE, a SEAD/UFRGS, junto a uma ampla equipe e setores institucionais, contribuiu para orientar, preparar e capacitar o corpo docente para o novo cenário de aulas virtuais. Nesse sentido, foram criadas orientações e um ambiente virtual específico sobre o assunto, aspectos que serão aprofundados na próxima seção.

\subsection{A Influência da EaD na implementação do ERE na UFRGS}

A necessidade de migração das aulas presenciais para o ambiente virtual surpreendeu a maioria das escolas e universidades brasileiras no final do primeiro trimestre de 2020 . No entanto, se a paralisação das atividades foi estabelecida dentro de uma mesma semana, a sua retomada no sistema de ERE ocorreu em tempos e condições bastante diversas. No caso da UFRGS, conforme já foi dito, o ERE entrou em vigor no mês de agosto, após meses de paralisação das atividades presencias de graduação. Suas atividades foram interrompidas, no ambiente presencial, em 15 de março de 2020. O retorno foi em 19 de agosto do mesmo ano, mais de 4 meses depois, o que viabilizou o planejamento das ações, por meio de um documento oficial redigido pelo CEPE, e a preparação dos professores através de uma série de cursos, materiais e tutoriais disponibilizados no site da instituição em um ambiente projetado pela SEAD/UFRGS, especificamente, para o ERE (UFRGS, 2020).

Durante esse período, uma série de documentos e recursos que buscavam regular, orientar e prepar docentes e discentes para o novo cenário foram sendo desenvolvidos. Além disso, buscou-se alternativas para ampliar o acesso dos estudantes em vulnerabilidade econômica aos recursos tecnológicos, destacando-se aqui o projeto Reconecta UFRGS (UFRGS, 2020). 
Em 27 de julho de 2020, o CEPE estabeleceu a regulamentação do ERE. Nesse documento, são apresentadas as decisões institucionais sobre carga horária presencial indispensável, necessidade de cancelamento de disciplina, flexibilização de pré- requisito, apoio para a acessibilidade e inclusão, realização de estágios, criação de uma Comissão de Acompanhamento do Ensino Remoto Emergencial, dentre outros pontos. Esta Comissão-ERE fica encarregada de emitir orientações sobre a regulamentação do ERE e encaminhar relatório ao CEPE, sendo composta por 22 membros que representam distintos órgãos de gestão e setores (Pró-Reitoria de Graduação, Câmara de Graduação, Secretaria de Educação a Distância, Pró-Reitoria de Assuntos Estudantis, Coordenadoria de Ações Afirmativas, Centro de Processamento de Dados, Fórum de Graduação, Departamentos, Representação Docente, Representação Técnico Administrativa e Representação Discente) (CEPE/UFRGS, 2020).

Nesse sentido, é apontada a necessidade de criação de cronograma e plano de ensino adaptados exclusivamente para o ERE e sua aprovação pelas Comissões de Graduação, prevendo-se a realização de atividades síncronas gravadas e assíncronas que mantenham os conteúdos e objetivos de aprendizagem da modalidade presencial. Para apoiar os professores nesse processo de adaptação, a SEAD/UFRGS centralizou, em um espaço do site institucional denominado Ensino Remoto UFRGS (Figura 1), uma série de dicas, informações de suporte técnico, legislação, orientações de segurança digital e tutoriais relacionados a esse cenário. Esse espaço é de acesso público, mas fica evidente que o principal foco é apoiar a prática do professor e, em menor dimensão, do aluno.

Figura 1 - Interface da página web Ensino Remoto UFRGS.

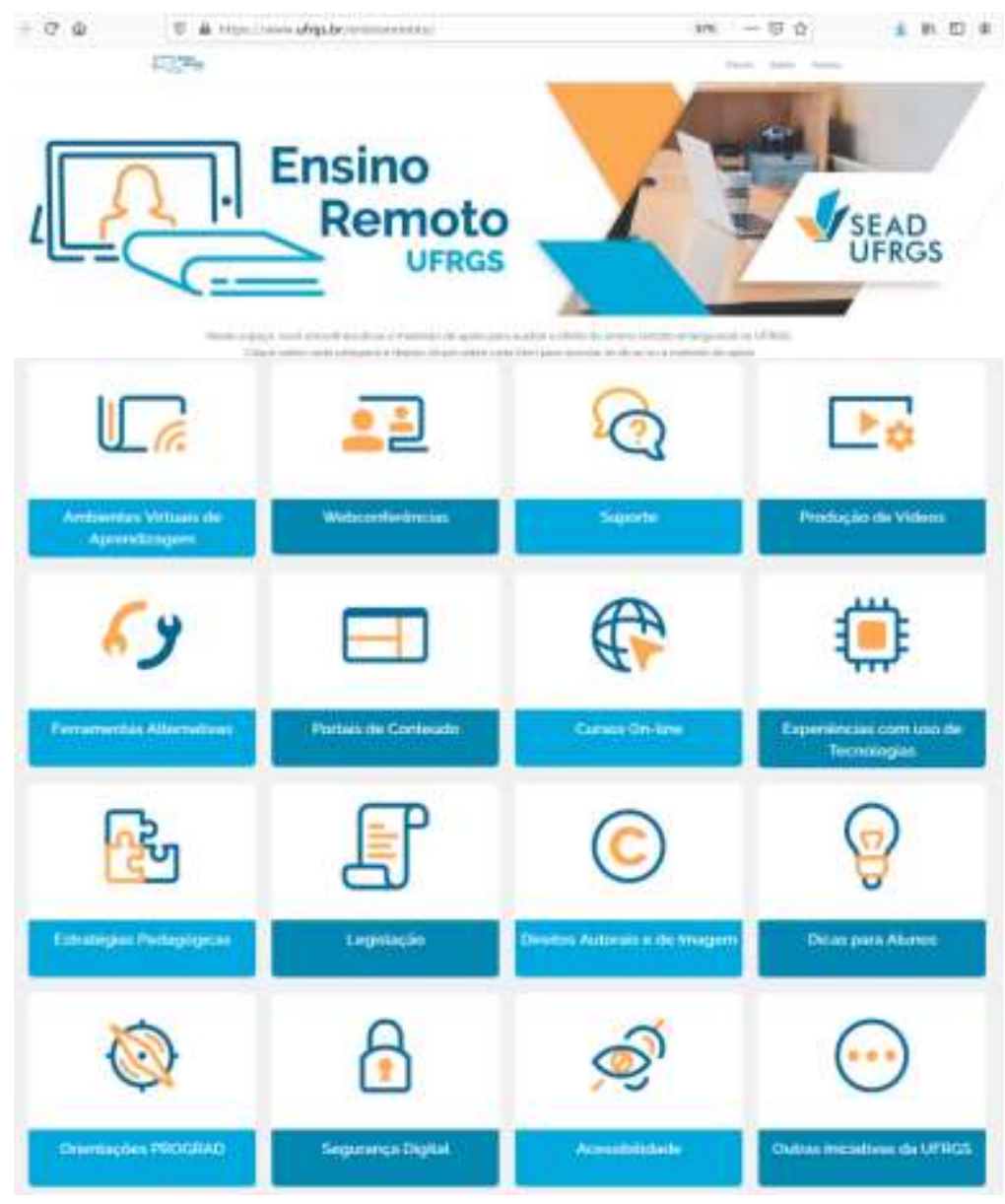

Fonte: UFRGS (2020). 
No espaço denominado "Orientações PROGRAD", por exemplo, são disponibilizadas diretrizes, tutoriais, modelos e materiais de apoio para várias demandas do ERE. Destaca-se aqui os tutoriais que orientam a revisão do plano de ensino e o acesso a um modelo em arquivo Word editável com as novas informações sobre direitos autorais e uso de imagem (também destacado na interface do Ensino Remoto UFRGS) e as orientações do CEPE sobre critérios de avaliação do aluno no cenário de ERE.

Em relação às webconferências para a realização das aulas síncronas, a Universidade sugere o uso do Google Meet, Microsoft Teams e MConf. No espaço dedicado a instruir os professores sobre o uso desses recursos (criar reuniões, gravar aulas, inserir gravações no AVA), são disponibilizados tutoriais específicos para cada ferramenta através de links para arquivos digitais em extensão pdf, vídeos no youtube e direcionamento para outros sites institucionais que organizam esses materiais. Observa-se que a maioria desses recursos foram criados a partir das demandas do ERE, mas outros já estavam previamente organizados pela instituição. Nesse caso, chama-se atenção para o MConf que, por ser um produto técnico de pesquisa realizada dentro da própria Universidade, já possuía um espaço específico no site onde eram organizados e disponibilizados esses materiais.

Para a bibliografia no ERE, o CEPE/UFRGS (2020) aponta a necessidade de ser acessível digitalmente através dos repositórios da Universidade ou de domínio público, bem como a possibilidade de serem disponibilizadas pelo docente, seguindo a legislação referente aos direitos autorais. Para orientar esse processo, é possível acessar, dentro de "Orientações PROGRAD", materiais de apoio e informações sobre o uso da biblioteca digital (inaugurada em 2002) por meio de um link que direciona o usuário para o site da Biblioteca UFRGS que incluiu orientações específicas aos docentes no ERE, incentivando o uso de recurso de busca integrada (Sabi+).

O AVA assume uma importância diferente na retomada das aulas no sistema de ERE, mesmo que muitos professores e alunos já estivessem familiarizados com o ambiente, por usarem há algum tempo. Segundo o CEPE/UFRGS (2020), esse ambiente deve disponibilizar o plano de ensino adaptado, informando as atividades previstas e as instruções para a realização dessas atividades, bem como o link para acesso quando houver o uso de recursos fora do AVA. Na página web do Ensino Remoto UFRGS, é possível acessar uma série de vídeos que explicam o que são, o que oferecem e como funcionam os principais recursos dos AVAs utilizados pela instituição. Nesse sentido destaca-se a grande quantidade materiais focados no uso do Moodle (AVA mais popular na UFRGS), mas também são apresentadas orientações sobre o uso do ROODA e da SAV. A análise dos vídeos e dos materiais relacionados aos AVAs mostra que a maioria dos recursos organizados foram desenvolvidos antes do ERE, evidenciando que o uso dos AVAs já era incentivado pela instituição.

No que diz respeito às avaliações, o CEPE/UFRGS (2020) ressalta a preferência pelas avaliações processuais, diversas e assíncronas, a partir de orientações do professor sobre como a atividade deve ser realizada. Além disso, flexibiliza-se o Controle de Matrículas, sendo prevista a possibilidade de zero crédito, denominada "Vínculo Acadêmico - 2020/1".

Para a organização de aula e atividades assíncronas, a página web do Ensino Remoto UFRGS oferece orientações sobre a produção e edição de vídeos por meio da apresentação dos aplicativos Loom, OBS Studio, dentre outros. Destaca-se aqui que a maioria dos tutoriais foram organizados em 2020, a partir da demanda do ERE que exigiu a produção de materiais audiovisuais em casa, sem os equipamentos e os profissionais que frequentemente colaboram na EaD.

Para apoiar os professores na condução de suas aulas, são indicados portais de conteúdos que oferecem uma série de objetos de aprendizagem. Além disso, são 
recomendadas ferramentas alternativas que podem apoiar os processos de ensino e aprendizagem, como é o caso do Mural, Kahoot!, Mentimeter e Prezi. Um vídeo complementar, produzido pela instituição no contexto de ERE, é disponibilizado para apresentar formas de uso e aplicação prática dessas ferramentas na educação.

Por fim, ressalta-se também os campos denominado "Estratégias pedagógicas" e "experiências com usos de tecnologias" que trazem, respectivamente, orientações para a adaptação das práticas docentes ao ERE e exemplos de práticas com o uso das tecnologias na educação. Nos dois casos, são utilizados uma série links para vídeos e tutoriais.

\section{CONSIDERAÇÕES FINAIS}

O uso efetivo das tecnologias na educação ainda encontra barreiras que devem ser superadas nas práticas docentes presenciais. Isso ficou evidente pela demanda de uso de tecnologias durante o ERE, fazendo com que muitos professores tivessem que (re)descobrir as possibilidades e aplicações dos recursos que sempre estiveram disponíveis em seus AVAs, bem como as ferramentas alternativas que já estavam na internet tempos antes da pandemia ser anunciada.

Com a análise do caso da UFRGS, fica evidente a importância da institucionalização da EaD para a implementação do ERE, pois a aprendizagem resultante do processo de implementação da $\mathrm{EaD}$ apoiou o rompimento de algumas dessas barreiras, na medida que sua infraestrutura e recursos humanos estavam preparados para apoiar os professores e prever as dificuldades inerentes ao processo emergencial de transpor as aulas presenciais para os ambientes virtuais.

A UFRGS acompanhou a evolução tecnológica de muitas décadas e, por meio da relação entre ensino, pesquisa e extensão não apenas usufruiu de seus benefícios na educação, mas também foi capaz de desenvolver recursos próprios e oferecer à comunidade uma série de ferramentas tecnológicas de apoio à educação, como é o caso do ROODA, do MConf e do NAVI.

Além disso, a criação da SEAD/UFRGS intensificou o debate sobre as melhores práticas em EaD e pesquisas para viabilizar a construção de novos conhecimentos que permitiram a criação da página web Ensino Remoto UFRGS. Esse espaço revela não apenas a capacidade de desenvolvimento de materiais e ações para a formação docente e apoio discente, mas também o diferencial de uma instituição que tem à disposição uma equipe multidisciplinar adequada para projetar a experiência da EaD e do ERE.

Por fim, ressalta-se que, mesmo não sendo sinônimos, o ERE precisou apoiar-se na aprendizagem institucional do EaD, a fim de qualificar o processo de ensino e aprendizagem mediado por TICs. Mesmo com distintos tempos de planejamento, infraestrutura tecnológica de apoio e preparação de alunos e professores, o ensino remoto tornou-se uma emergência possível de ser atendida graças a uma longa história de avanços tecnológicos, investimento em infraestrutura e conhecimentos que prepararam algumas instituições para essa grande ruptura nas práticas de educação.

\section{REFERÊNCIAS}

ALVES, L. Educação a distância: conceito e história no Brasil e no mundo. v. 10 2011. Disponível em: http://seer.abed.net.br/index.php/RBAAD/article/view/235/113. Acesso em: 24 nov. 2020. 


\section{EmRede \\ Revista de Educação a Dístâncias}

BEHAR, P. A. Modelos pedagógicos em educação à distância. In: BEHAR, P. A. e cols. Modelos pedagógicos em educação à distância. Porto Alegre: ARTMED, 2009.

BEHAR, P. A.; PINHEIRO, A.; BITTENCOURT, J. V.; KIST, S. O. Construyendo una Interface para el Ambiente Virtual ROODA - Rede COOperativa De Aprendizagem. Revista Informática na Educação: Teoria \& Prática, Porto Alegre, v. 6, n. 1, p. 23-40, jan/jun 2003.

BOTTIN, F. DARONCO, L.; ROESLER, V. Mconf-Web: uma ferramenta para gerência de

webconferência. In: $17^{\circ}$ Brazilian Symposium on Multimedia and the Web. X Workshop on Tools and Applications. 2011. Disponível em:

https://sol.sbc.org.br/index.php/webmedia_estendido/article/view/5004/4910. Acesso em: 1 dez. 2020.

BOZKURT, A.; SHARMA, R. C. Emergency remote teaching in a time of global crisis due to CoronaVirus pandemic. Asian Journal of Distance Education, v. 15, n. 1, 2020.

BRASIL. Ministério da Educação - MEC, Secretaria de Educação a Distância. Referenciais de qualidade para educação superior a distância, 2007. Disponível em:

http://portal.mec.gov.br/seed/arquivos/pdf/legislacao/refead1.pdf. Acesso em: 26 nov. 2020.

CARNEIRO, M. L. F.; SILVEIRA, M. S. Objetos de Aprendizagem como elementos facilitadores na Educação a Distância. Educar em Revista. Edição Especial, Curitiba, n. 4 p. 235-260, 2014. Disponível em: https://repositorio.pucrs.br/dspace/bitstream/10923/13933/2/Objetos_de_Aprendiza gem_como_elementos_facilitadores_na_Educacao_a_Distancia.pdf. Acesso em: 1 dez. 2020.

CEPE/UFRGS, 2020. Conselho de Ensino Pesquisa e Extensão da universidade Federal do rio Grande do Sul. Resolução $\mathbf{n}^{\circ} \mathbf{2 5}$, de $\mathbf{2 7}$ de julho de 2020. Disponível em: http://www.ufrgs.br/cepe/res-025ensino-remoto- emergencial-ere-versao-página. Acesso em: 1 dez. 2020.

FALAVIGNA, G. Inovações centradas na multimídia: repercussões no processo ensino-aprendizagem. Porto Alegre: EdiPUCRS, 2009.

FERRREIRA, D. H. L.; BRANCHI, B. A.; SUGAHARA, C. R. Processo de ensino e aprendizagem no contexto das aulas e atividades remotas no Ensino Superior em tempo da pandemia. Revista Práxis, v. 12, n. 1 (Sup.), dezembro, 2020. Disponível em: http://revistas.unifoa.edu.br/index.php/praxis/article/view/ 3464/2700. Acesso em: 30 jun. 2021.

GIL, A. C. Métodos e Técnicas de Pesquisa Social. São Paulo: Atlas, 2009.

HODGES, C.; MOORE, S.; LOCKEE, B.; TRUST, T.; BOND, A. The Difference Between Emergency Remote Teaching and Online Learning, Educause Review, 2020. Disponível em:

https://er.educause.edu/articles/2020/3/the-difference-between-emergency- remote-teaching-andonline-learning. Acesso em: 29 nov. 2020.

MACHADO, D. P.; MORAES, M. G. Educação a distância: fundamentos, tecnologias, estrutura e processo de ensino e aprendizagem. São Paulo: Érica, 2015.

MATTHEWS, M. T; COURTNEY, M. Empathy in Distance Learning Design Practice. TechTrends. 2017. p. 486-493.

MOORE, J.L.; DICKSON, C.; GALYEN, K. e-Learning, online learning, and distance learning environments: Are they the same? Internet and Higher Education. 2011. p. 129-135.

MOREIRA, J. A.; SCHLEMMER, E. Por um novo conceito e paradigma de educação digital onlife. In: Revista UFG, v. 20, 63438, 2020. Disponível em: https://www.revistas.ufg.br/revistaufg/article/ view/63438. Acesso em: 1 jul. 2021. 
NETTO, A. A. O. Novas tecnologias \& universidade: da didática tradicionalista à inteligência artificial: desafios e armadilhas. Petrópolis: Editora Vozes, 2005.

NYE, D. E. Technology Matters: questions to live with. London: The MIT Press: 2006.

RONDINI, C. A; PEDRO, K. M; DUARTE, C. S. Pandemia da Covid-19 e o Ensino Remoto Emergencial: mudanças na prática pedagógica. Interfaces Científicas. v. 10 n. 1, 2020, p. 41-57. Disponível em: https://periodicos.set.edu.br/educacao/article/view/9085/4128. Acesso em: 30 nov. 2020.

RODRIGUES, R.C. Educação à distância em cursos presenciais do ensino superior: uma análise de estratégias pedagógicas não presenciais. 2002. 145f. Dissertação (Mestrado em Educação) Faculdade de Educação, Universidade Prebiteriana Mackenzie, São Paulo, 2002.

SANTINELLO, J. Ensino Superior em Ambientes de Apredizagem (AVAs): formação docente universitária em construção. Curitiba: InterSaberes, 2015.

SEAD. UFRGS. Secretaria de Educação a Distância. Disponível em: http://www.ufrgs.br/sead. Acesso em: 1 dez. 2020.

TAPSCOTT, D. Geração Digital: a crescente e irreversível ascensão da geração net. São Paulo: Makron Books, 1999.

UFRGS. Relatório de Gesão - Exercício 2019. Disponível em: https://lume.ufrgs.br/bitstream/handle/10183/213040/001117474.pdf?sequence=1\&i sAllowed=y Acesso em: 1 dez. 2020.

UFRGS. UFRGS em Números. 2020. Disponível em: https://www1.ufrgs.br/paineldedados/ ufrgs_numeros.html Acesso em: 1 dez. 2020

WHITTLE, Clayton et al. Emergency Remote Teaching environment: a conceptual framework for responsive online teaching in crisis. Disponível em: https://www.emerald.com/insight/content/doi/10.1108/ILS-04-2020- 0099/full/pdf?title=emergencyremote-teaching-environment-a-conceptual-framework-for-responsive-online-teaching-in-crises. Acesso em: 30 nov. 2020. 